\title{
Physiological Signal Monitoring in the Waiting Areas of an Emergency Room
}

\author{
Dorothy Curtis, Eugene Shih, \\ Jason Waterman, John Guttag \\ Massachusetts Institute of Technology \\ CSAIL \\ Cambridge, MA, USA \\ 1-617-253-0541 \\ \{dcurtis,eugene,jwaterman, \\ guttag\}@csail.mit.edu
}

\author{
Jacob Bailey, Thomas Stair \\ Brigham and Women's Hospital \\ Emergency Department \\ Boston, MA, USA \\ tstair@partners,org. \\ jacob.m.bailey@gmail.com \\ Lucila Ohno-Machado \\ Brigham and Women's Hospital \\ Decision Systems Group \\ Boston, MA, USA \\ machado@dsg.harvard.edu
}

\author{
Robert A. Greenes \\ Arizona State University \\ Department of Biomedical Informatics \\ Phoenix, AZ USA \\ greenes@asu.edu
}

\begin{abstract}
The Scalable Medical Alert and Response Technology (SMART) System was developed to monitor physiological signals from patients in the waiting areas of an emergency department. The system monitors the $\mathrm{SpO}_{2}$ (oxygenation level in the blood), ECG (electrical activity of the heart) and the location of multiple patients wirelessly. It was deployed at the Brigham and Women's Hospital in Boston, MA, between June, 2006, and December, 2007. This paper describes the overall architecture, the sensors used, challenges in deploying this technology in a hospital and the degree of patient acceptance. Some sections of this article are based on an article first published in the Journal of the American Medical Informatics Association (J Am Med Inform Assn: 2008; 1) [7].
\end{abstract}

\section{Keywords}

Physiological signal monitoring, sensor network.

\section{INTRODUCTION}

According to the Institute of Medicine [15], "Emergency Department (ED) visits in the US grew by 26 percent between 1993 and 2003. But over the same period, the number of EDs decreased by 425." This increase in ED usage typically means that a patient spends an increasing amount of time in the waiting area of an ED before being seen: he is often triaged promptly, but then may wait several hours before seeing a physician. A national hospital ambulatory medical care survey [19] reports that, "Overall, patients spent an average of 3.2 hours in the Emergency Room.”

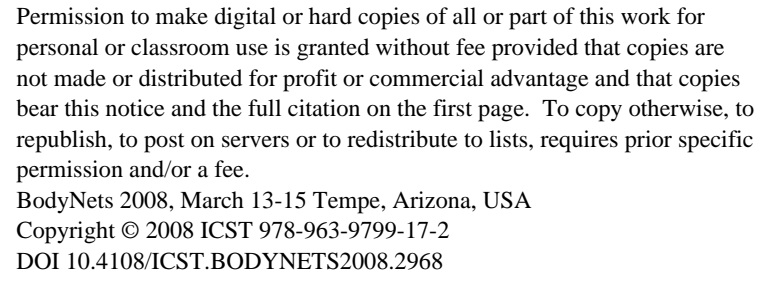

Because a patient's status may deteriorate during this waiting time and because ED personnel are typically quite busy, it seemed useful to assess whether computer-aided monitoring of the patients in the waiting area of an ED was feasible: whether a costeffective system could be built, whether it would be acceptable to patients and whether it would be useful to the ED staff.

The SMART (Scalable Medical Alert and Response Technology) system monitors the $\mathrm{SpO}_{2}$ (oxygenation level in the blood), the ECG (electrical activity of the heart) and the location of multiple patients. The data are sent wirelessly to a central computer that collects the data and analyzes it. If an abnormal situation is detected, the system alerts a caregiver.

In addition to being useful in the emergency room waiting area, the SMART System can be used at a disaster site and during transport to a hospital. For these environments, it is useful for the SMART system to be wearable, easily deployed, low cost, low power, and reasonably accurate.

The challenges in developing a system for monitoring physiological signals in these environments include

- $\quad$ Selecting appropriate sensors

- Integrating diverse components

- Deploying adequate networking infrastructure

- $\quad$ Processing the collected data and presenting appropriate alerts and visual information

In addition, because the point of this project was to prove feasibility by deploying this system in an environment where it would be used by actual patients, the emphasis was not on perfecting any particular component, but on completing the integration of the components and doing a study at a hospital. The goal of the study was to assess acceptability to patients and the general usability of the system. 
This paper describes the architecture of the SMART system, the sensors used in this system, the challenges of deploying it in a hospital environment and some results related to patient acceptance.

\section{ARCHITECTURE}

Figure 1 shows the main components of the SMART System architecture. The system consists of a patient monitoring device, a location subsystem, a wireless networking subsystem, decision support and logistic support subsystems (SMART Central), and a caregiver module. The system also has a logging subsystem. The location system is based on active tags, and provides location information about both patients and caregivers. Patient data including ECG signals, $\mathrm{SpO}_{2}$ readings, and location information flow into SMART Central. The Streaming Data Manager inside SMART Central receives the streams of data from patients and caregivers, processes them and makes them available to other modules for further analysis and logging.

The patient wears a waist pack, or pouch, containing a PDA and hardware that captures the data from the sensors worn by the patient. A healthy volunteer wearing the waist pack is shown in Figure 2. The location system in the emergency room is available from Sonitor[26]. The location tag is worn on a lanyard around the patient's neck. The networking used in the emergency room is standard 802.11b. SMART Central is a standard PC. The sensors are more completely discussed in the Sensors section. During ambulance transport, GPS is used for location and EVDO is used for data transfer.

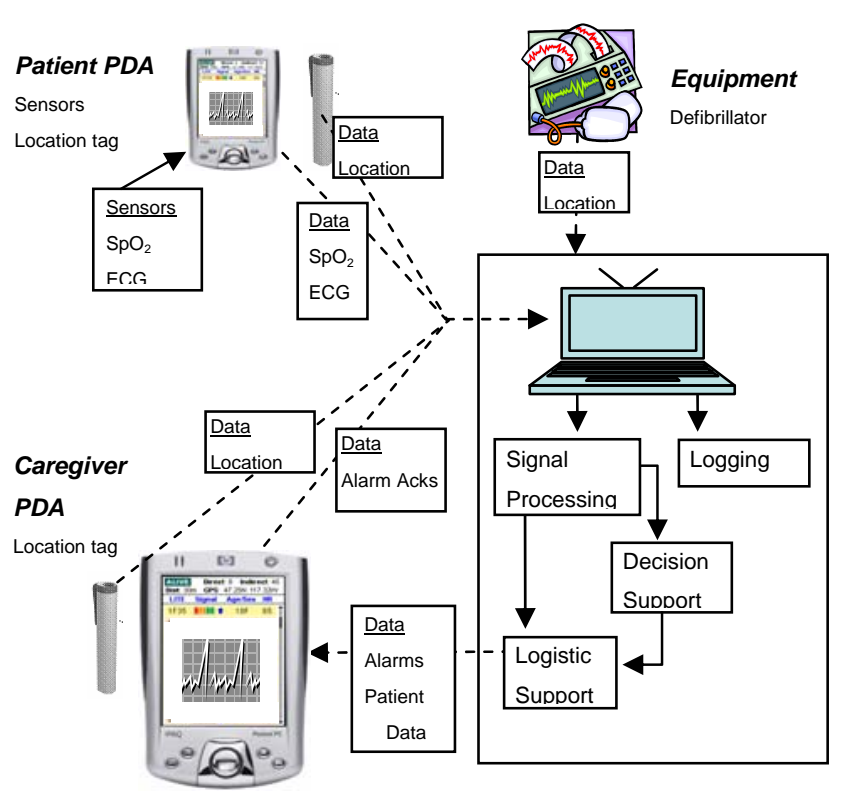

Figure 1. SMART components: Caregiver PDAs, location sensors and patient PDAs with ECG and $\mathrm{SpO}_{2}$ sensors are wirelessly connected to SMART Central where all data are processed.

\section{SENSORS}

In reviewing potential types of sensors for monitoring patients with shortness of breath and/or chest pain, we considered $\mathrm{SpO}_{2}$ sensors. They measure oxygenation as a percent of a maximum value and acceptable readings are between $90 \%$ and $100 \%$. Readings below $90 \%$ are cause for concern. One limitation of these sensors is that they are not "early-warning" indicators of problems, but rather give "late-warnings." The physicians on our team would have preferred a sensor that measured blood pressure, but we did not find an acceptable one.

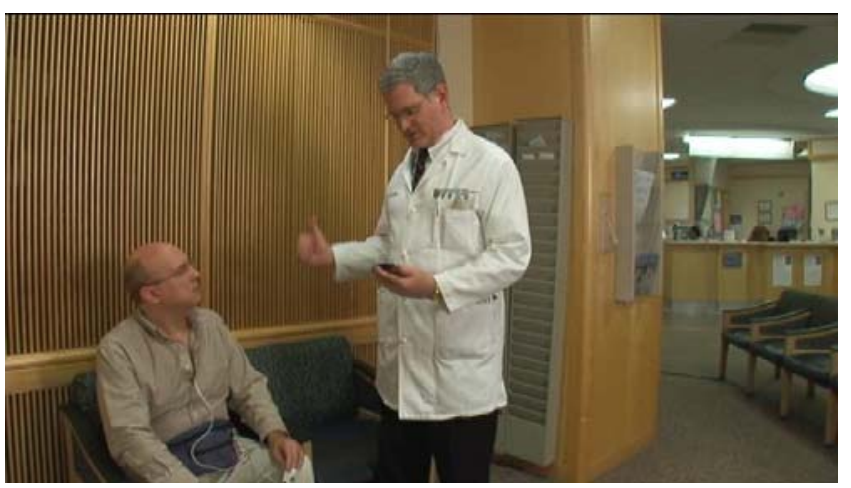

Figure 2. Patient wearing SMART monitoring gear: $\mathrm{SpO}_{2}$ and ECG sensors, and a waist pack with sensor box and $H P{ }^{\circledR}$ iPAQ ${ }^{\circledR}$.

The other sensor that the physicians wanted was one that provided an ECG waveform. While there are commercially available heart rate sensors based on ECG information, the physicians believed that the waveform would be more useful because of the additional morphological information.

The criteria for choosing specific sensors required that they be low-cost, low-power, sufficiently accurate, light-weight, convenient to use in a waiting area and that we could integrate them with the rest of the system. For the PDA, the goals were programmability, low-cost, built-in wireless capability, reasonable battery life, powerful enough computation for this application and enough ports to integrate the sensors.

The PDA we chose is HP's iPAQ model 5500. This PDA has appropriate amounts of memory, built-in wireless communications (802.11b), and expandability to include additional CF or PCMCIA cards. The PDA runs Familiar Linux [12].

The sensor box contains two AA batteries to power the $\mathrm{SpO}_{2}$ sensor and the electronics for the three electrode ECG sensor. The electrodes for the ECG sensor run from the sensor box to the patient's skin. The $\mathrm{SpO}_{2}$ sensor communicates with the sensor box via RS232. The sensor box also contains a Cricket Mote $[25,6]$ for collecting the ECG data and passing it to the PDA. The sensor box is cabled to the PDA via RS232. The Cricket Mote runs TinyOS: we added a module to transfer data from the daughter card, assemble it in to packets and send the packets via RS232 to the PDA.

The $\mathrm{SpO}_{2}$ sensor that we use is manufactured by Nonin [23]. We chose their ipod product. This finger sensor uses infra-red light to detect oxygenation level and heart rate. It also provides information about the sensor's status. The data is three bytes and it is sent three times per second. It draws $60 \mathrm{~mW}$ under typical operating conditions. It has a three wire interface: power (2- 
6VDC), ground, and RS232 (or TTL) serial data output. Because we were concerned that having a cable running from the patient's finger to the fanny pack would be inconvenient for the patient, we investigated Nonin's 4100 Bluetooth oximeter. However, the bluetooth communications with the PDA proved unreliable and the battery housing on the sensor was a bit bulky.

The ECG sensor was developed by our group at MIT, since a lowcost commercially available sensor was not available. The ECG is based on the AD620 Instrumentation Amplifier from Analog Devices [1]. We started with two electrodes on the patient, but switched to using three electrodes to decrease the noise in the signal. This sensor is implemented as a daughter card for a Cricket mote. The Cricket mote collects 12-bit data samples from the ECG sensor 200 times per second. This rate is acceptable for "monitoring" quality ECG data, but too low for "diagnostic" quality ECG data. The PDA reads the ECG data over a serial line from the Cricket mote. The PDA then groups this data into packets of 20 samples and sends it to SMART Central. Although we used high quality electrodes and electrode wires, the signal from the ECG sensor is not as good as that from commercial devices. It is sufficiently accurate to support certain types of arrhythmia monitoring for the ED, but it is not of sufficiently high (“diagnostic") quality for detecting atrial fibrillation and other more subtle diagnoses. This sensor is also sensitive to motion: patient movements including walking, moving an arm, and chest muscle activity add large amplitude signals to the ECG.

The patient PDA's battery has a lifetime of three to four hours. This was adequate for our deployment. The batteries in the sensor box last several weeks under typical usage.

We had a variety of reliability problems prior to deployment. These seemed related to transporting the equipment from one location to another and, perhaps, associated temperature changes. Once deployed, the system ran adequately and, to some degree, the reliability of some components was not stressed as we monitored only a few patients per day and, if one patient PDA was not working, another one could be substituted.

\section{NETWORKING}

The main requirement for the network infrastructure is to transmit vital signs data from the patient PDAs to SMART Central. The needed bandwidth is estimated as follows: 10 ECG messages per second, three $\mathrm{SpO}_{2}$ messages per second and at most one battery message per second per patient with a maximum of ten patients. Each message contains fewer than 400 bytes. With eight bits per byte, this is an aggregate of less than $0.5 \mathrm{Mbps}$. The standard TCP protocol [9] is used to transmit this data. We chose TCP because we wanted a complete record of the data collected. From time to time there were some gaps in the displayed data as TCP recovered from errors, but this seemed acceptable to the users. The patient data does not carry any patient identifiers and is sent unencrypted. Using SSL [28] to encrypt this traffic in the future would be straight-forward. An off the shelf $802.11 \mathrm{~b}$ wireless router receives this data from the patient PDAs and sends it via a wired connection to SMART Central. The wired connection was implemented after observing lossy behavior when that connection was wireless during some test sessions.

The network infrastructure for communicating location information uses ultrasound to communicate tag identifiers from the patients to the location detectors that are mounted on the walls. These detectors use the $802.11 \mathrm{~b}$ wireless infrastructure to send information about tag "sightings" to SMART Central. The 802.11b wireless network is also used to communicate alerts and patient information to caregiver PDAs. The traffic for location detection and for communicating with up to two caregivers is significantly less than one patient's vital signs data. The communication stream between SMART Central and the caregiver PDAs uses TCP and is SSL encrypted, as it contains patient identifying data.

The PDA's clock is synchronized with SMART Central via the standard NTP protocol [21]. The PDA time stamps the data collected from the sensors and the time stamped data is forwarded to SMART Central.

\section{SOFTWARE}

SMART Central, the software core of the SMART system, runs under the Linux ${ }^{\circledR}$ Operating System on a commodity PC. The main components of SMART Central are a Streaming Data Manager, and two decision support components: a patient-specific Decision Support Module and a Logistics Support Manager. The Streaming Data Manager receives the real-time patient data, processes it, and forwards it to the Decision Support Module. The Decision Support Module then analyzes the data and triggers alarms. The Logistic Support Manager matches alarms to the environment to dispatch relevant information to the appropriate caregiver. All data and alarms are logged for later review and analysis.

The Streaming Data Manager receives the $\mathrm{SpO}_{2}$, ECG, and location data streams. The $\mathrm{SpO}_{2}$ data stream provides both the patient's oxygenation level and the patient's heart rate. The ECG sensor provides waveform data. The location data stream shows the tag id, status and signal strength of each tag transmission received by the location system detectors. The Streaming Data Manager delivers raw data and derived measurements in response to a simple queries.

Figure 3. Inside the patient waist pack: $\mathrm{SpO}_{2}$ and ECG sensors, sensor box and $H P{ }^{\circledR} \mathrm{iPAQ}{ }^{\circledR}$.

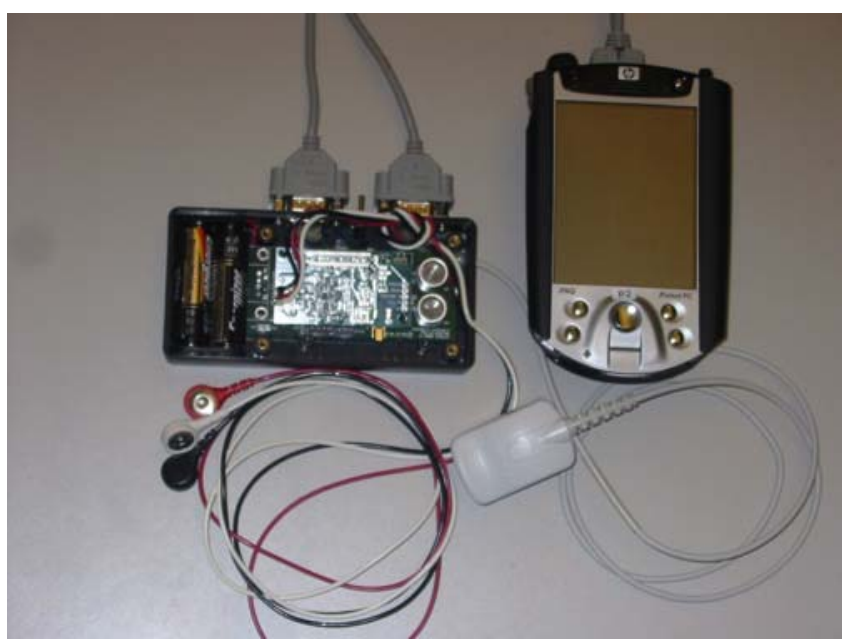


The Streaming Data Manager module incorporates a computation module for detecting heart beats in the ECG waveform data using a modified version of the SQRS algorithm [10, 24], a real-time algorithm for QRS detection. The algorithm is able to report QRS complexes and QRS-like artifacts, and generates a warning when no beats are detected over any three second interval. This warning may indicate that the patient's heart is not beating or it may indicate a technical problem.

SMART Central's Decision Support Module analyzes streams of data to detect alarm conditions and uses a set of rules to generate alarms. Alarms are divided into two categories: technical and medical. Technical alarms are caused by low battery, sensor removal, etc. The rules for detecting alarms are described in Table 1.

The Decision Support Module sets up long-running queries to the Streaming Data Manager to receive data streams for the ECG waveform, the detected heart beat positions (times), the $\mathrm{SpO}_{2}$ sensor information, and location information. In the Decision Support Module, the data are combined and new higher level data are generated. A robust heart rate is obtained by using a median filter to mask missed or extra beats detected by the Streaming Data Manager. The Decision Support Module monitors and generates alarms about a patient's cardiac status by evaluating the $\mathrm{SpO}_{2}$, ECG and heart rate data streams. Other intermediate parameters obtained from the ECG waveform and the heart beat positions by the Decision Support Module are:

- $\quad$ Skewness: The histogram of a normal ECG's data has a distribution with most of its data around the basal depolarization voltage. Skewness under 0.5 (symmetric distribution) of this data in a two second window is considered abnormal and is likely to indicate noise.

- Width: If the width of a QRS complex is over $120 \mathrm{~ms}$, the beat is marked as abnormal.

- Irregularity: If the standard deviation of successive time differences between normal beats in an 8 second window is over 0.4 seconds, the series is marked as irregular.

- $\quad$ Saturation: If the measured ECG voltage changes rapidly between the maximum and minimum possible values for this sensor, the data are marked as saturated. Again, this is likely to indicate noise.

Skewness and saturation are most likely signs of excessive noise in the ECG signal and indicate technical problems with the ECG sensor, or, more often, patient arm motion. Abnormal width and irregularity are likely to be indicators of medical problems.

In cases where the ECG waveform and derived data are out of the normal range for the patient, the software consults the $\mathrm{SpO}_{2}$ readings and decides whether to generate a medical alarm or just a technical alarm. The technical alarm would indicate that the data from the different sensors doesn't match and that the sensors should be checked. In our experience, the readings from our $\mathrm{SpO}_{2}$ sensor have been far more stable than those from the ECG. The combination of a damped sensor and a volatile sensor allows the SMART system to present a more accurate picture of the patient than either sensor by itself.

The Decision Support Module also combines location data from different location detectors to compute the position of the patient. A large room typically has several detectors, and the location within the room is based on the amplitude of the signals from each detector.

At the BWH ED, the main waiting area has two detectors, which gives us two "zones" for tracking. There are also detectors in the restrooms, the triage rooms, the family room, the area near the registration desk, and several locations along the way from the waiting area to the nearby cafeteria.

The location sensor provides an accelerometer. This sensor indicates whether the person is walking, but does not detect arm motion or chest muscle activity. Thus it is too "coarse-grained" to help in reducing false alarms associated with noise in the ECG signal. There is also room for an accelerometer on the ECG board, but we are uncertain that this will be sufficient to help us recognize noise in the ECG signal associated with arm movement and chest muscle flexion.

The Logistic Support Manager is responsible for dispatching alarms to the appropriate personnel. Unlike the Decision Support Module, which deals with patient-specific data that are independent of the environment, the Logistic Support Manager is highly environment-dependent, and incorporates workflow rules. These rules can be easily changed. In our deployment, the rules indicate that the alarm should be sent to the nearest available caregiver. The rules can also describe an escalation procedure in case a caregiver does not respond to an alarm.

Table 1. Rules for generating alarms

\begin{tabular}{|l|l|}
\hline Oximeter Medical Alarms & Condition that triggers the alarm \\
\hline High HR & $\begin{array}{l}\text { Heart rate from oximeter sensor } \\
\text { above patient-specific threshold } \\
\text { (default threshold is 100bpm) }\end{array}$ \\
\hline Low HR & $\begin{array}{l}\text { Heart rate from oximeter sensor } \\
\text { below patient-specific threshold } \\
\text { (default threshold is 60bpm) }\end{array}$ \\
\hline Low SpO 2 & $\begin{array}{l}\text { Oxygen saturation below patient- } \\
\text { specific threshold (default threshold } \\
\text { is 90\%) }\end{array}$ \\
\hline ECG Medical Alarms & No beat detected in 3 seconds \\
\hline Asystole & $\begin{array}{l}\text { ECG shows artifacts, abnormal } \\
\text { skewness, wide waves or no waves, } \\
\text { lacks QRS complexes, and the SpO } \\
\text { heart rate is missing or below } \\
\text { 20bpm or above 150bpm }\end{array}$ \\
\hline Ventricular Fibrillation & $\begin{array}{l}\text { ECG has wide QRS complexes and } \\
\text { heartrate is over 100bpm }\end{array}$ \\
\hline Tentricular Tachycardia & $\begin{array}{l}\text { ECG heart rate above patient- } \\
\text { specific threshold (default threshold } \\
\text { is 100bpm) }\end{array}$ \\
\hline Tachycardia & $\begin{array}{l}\text { ECG heart rate below patient- } \\
\text { specific threshold (default threshold } \\
\text { is 60bpm) }\end{array}$ \\
\hline Irregular & $\begin{array}{l}\text { ECG QRS complexes are irregularly } \\
\text { spaced }\end{array}$ \\
\hline Bradycardia & $\begin{array}{l}\text { ECG diagnosis inconsistent with } \\
\text { SpO } 2 \text { heart rate: }\end{array}$ \\
\hline
\end{tabular}




\begin{tabular}{|l|l|}
\hline & $\begin{array}{l}\text { (a) if ECG indicates asystole and } \\
\text { oximeter heart rate is between } \\
\text { 20bpm and 150 bpm, or } \\
\text { (b) if ECG indicates ventricular } \\
\text { fibrillation and oximeter heart rate } \\
\text { is between 20bpm and 150 bpm }\end{array}$ \\
\hline Noisy & $\begin{array}{l}\text { Artifacts and normal skewness in } \\
\text { ECG signal }\end{array}$ \\
\hline Leads Off & ECG lead is off (signal is saturated) \\
\hline Nosignal & No ECG data received \\
\hline Technical $\mathrm{SpO}_{2}$ & $\begin{array}{l}\text { Oximeter sensor removed from } \\
\text { finger }\end{array}$ \\
\hline $\begin{array}{l}\text { AWOL (away without } \\
\text { leave) }\end{array}$ & $\begin{array}{l}\text { No communication between PDA } \\
\text { and SMART Central }\end{array}$ \\
\hline Battery & Low battery (below 20\%) \\
\hline
\end{tabular}

Currently, if a caregiver "responds" to an alarm, re-notification of most alarms is suppressed for ten minutes. The exceptions are AWOL (Away With Out Leave) and battery low. The Logistic Support Manager matches alerts to the appropriate caregiver and sends the alert information to that Caregiver PDA. A summary of outstanding alerts is also available on the SMART Central display. Figure 4 shows one of the interfaces available at SMART Central. Descriptions of the SMART system user interfaces are available in [7].

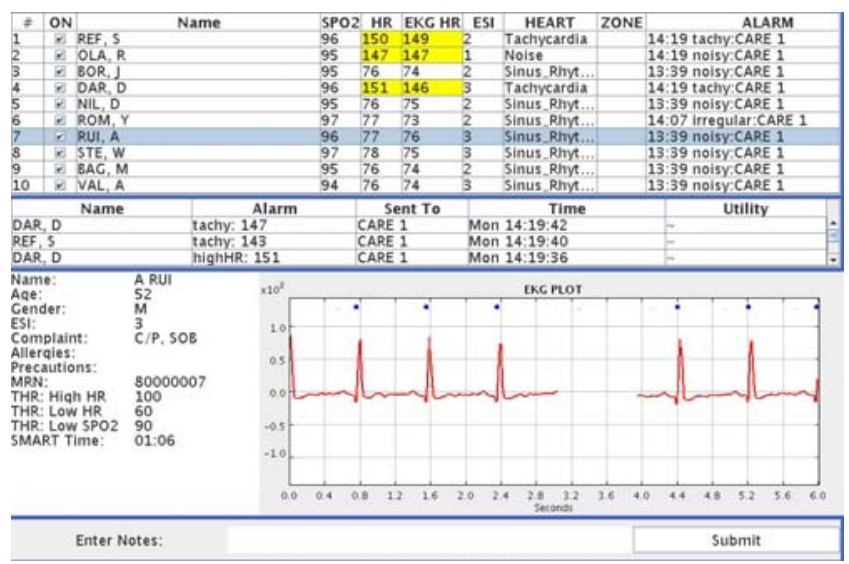

Figure 4: SMART Central User Interface

One observation about using the $\mathrm{SpO}_{2}$ sensor was that patients tended to shift the sensor from one finger to another. Initially, this resulted in too many alarms. This caused us to adjust the amount of time the alarm condition had to persist before Logistic Support Manager sent an alarm to the caregiver. For some patients, the finger sensor was somewhat unreliable, due to decreased blood flow in their fingers. In the future, we would like to integrate an ear-lobe based $\mathrm{SpO}_{2}$ device from Nonin to handle these situations. Similarly, for some patients, the ECG signal amplitude was very small. In the future we would like to provide a method for adjusting the amplitude to compensate for this problem. While some auto-scaling algorithm might work, we will have to be careful to avoid amplifying low-amplitude noise.

Patient-specific thresholds and parameters helped us decrease the number of false alarms in patients with known medical problems, such as irregular heart beats.

\section{DEPLOYMENT}

To evaluate the SMART system in a real environment, we needed approval from the Institutional Review Board (IRB) at Brigham and Women's Hospital. The approval process led to several constraints on how SMART would be deployed:

1) In order to ensure that SMART could not interfere with Emergency Department operations

a. Physicians did not carry PDAs to receive alarms

b. Communications was done over a private local area network

2) A dedicated paramedic operated the system because the IRB did not want patients being monitored without a person overseeing the operation

While these goals prevented the evaluation of certain aspects of the SMART system, having a paramedic on site provided good feedback about the usability of the system. We also surveyed the patients about their experience during the time they were monitored.

Another challenge in deploying and operating the location systems was that the hospital had chosen another location system to be deployed hospital-wide and therefore support for additional wiring that would have been desirable for the best operation of the Sonitor [16] location system was not provided.

Initially, the SMART operator could sit so that he could visually observe patients. Later, due to security concerns, the hospital required that a door be closed so that the SMART operator is in a place where he can not see the patients directly. This makes it a little more difficult for him to resolve false alarms.

One consequence of being on a private subnet was that the SMART operator needed to use an extra laptop to interact with the hospital's information system, e.g., to find suitable candidates for monitoring. Further, we could not automatically transfer registration information from the hospital system to the SMART system, so patient information had to be entered by hand.

Prior to deployment, we conducted nine exercises with healthy volunteers. During these tests up to ten volunteers wore patient waist packs and the SMART system recorded their vital signs and locations. The SMART operator reviewed the display of the data as it was received by SMART Central. He also received appropriate alerts when volunteers removed sensors.

\section{RESULTS}

Evaluation of the SMART System was conducted in the waiting area of the Emergency Department at the Brigham and Women's Hospital in Boston. A patient was eligible for enrollment in the study if he or she had completed triage and had complaints of shortness of breath or chest pains.

The goals of this preliminary evaluation were (1) to determine patient acceptance, (2) to assess the interpretability of the raw signals, (3) to evaluate the adequacy of the patient location 
system, and (4) to assess the appropriateness of the various alerts (technical and medical) that were generated.

The workflow can be summarized as follows: When a patient arrives at the BWH ED, he gives his name and his chief complaint to the receptionist. The triage nurse then talks with and examines the patient briefly and assigns a triage category to the patient. The BWH ED assigns triage categories per the Emergency Severity Index (ESI) [27, 30]. This index ranges from 1 to 5 (1 being the most severe, representing patients who need to be seen immediately by a physician. Those triaged in categories 2-5 are assigned to the waiting area until they are admitted to the Emergency Department.

Patients eligible for the SMART study included those triaged in categories 2-4, as assessed by the triage nurse, and presenting with chest pains or shortness of breath. The patients were asked to complete a survey at the end of their participation.

The raw data collected from the patients, both vital signs and location information, the derived data computed by the SMART system, the caregiver interactions with the system, and the surveys were recorded in a database for later analysis. Given the relatively small number of patients and the anticipated infrequency of significant alert conditions, we did not expect to find very many true positive events. Thus a primary focus was on reducing false positives of both technical and medical kinds.

During the evaluation period, June, 2006 through December, 2007, the SMART Operator approached 124 eligible patients for their consent to participate in the study. 44 patients declined. Consents were obtained from 180 patients. One patient who consented terminated his participation before wearing the pouch. Seven patients who consented were brought back into the ED before having the opportunity to wear the pouch. The remaining 172 patients wore the pouch between 5 minutes and 3 hours. For this group, all but four patient sessions ended because a bed in the ED became available. Three patients withdrew from the study for the following reasons: 1) "got tired of wearing the monitor", 2) "wait was too long”, and 3) "device was irritating." The first two then left the Emergency Department altogether.

When a bed in the ED became available for the patient, the SMART pouch was removed and the patient completed some survey questions. We collected demographic information and system acceptance data. Of the patients who wore pouches, 99 completed surveys. Their ages ranged from 18 to 87 with an average of 50 (12 omitted their age), there were 40 males and 52 females (7 omitted their gender). During the past year, 39 had never visited a hospital emergency department, 17 had visited once, 21 had visited twice, 6 had visited three times, 4 had visited four times and 11 had visited more than four times. One declined to respond.

While some patients used medical devices at home, most did not: of the 97 patients who responded to the question about using a medical device at home, only 14 out of 97 used one or more devices at home. The devices the patients use at home include: a nebulizer, oxygen, CPAP (continuous positive airway pressure) and BiPAP (Bi-level positive airway pressure) machines, an IV Pump, blood pressure monitors, a spirometer, a dialysis cycler and a glucometer.

We asked whether the patients would wear the monitoring system again. Of the 95 patients who responded to this question, 91 patients responded with "would wear" or "probably would wear" the monitoring system again.

In three cases, alarms were deemed serious enough to request reprioritization of patients. In all three cases the medical staff accepted the reprioritization.

In one case SMART was easily used to investigate a patient's complaint. In this case the patient complained that her pacemaker was not working. Figure 5 shows that each time her heart rate dips below 60 beats per minute, the pacemaker kicks in.
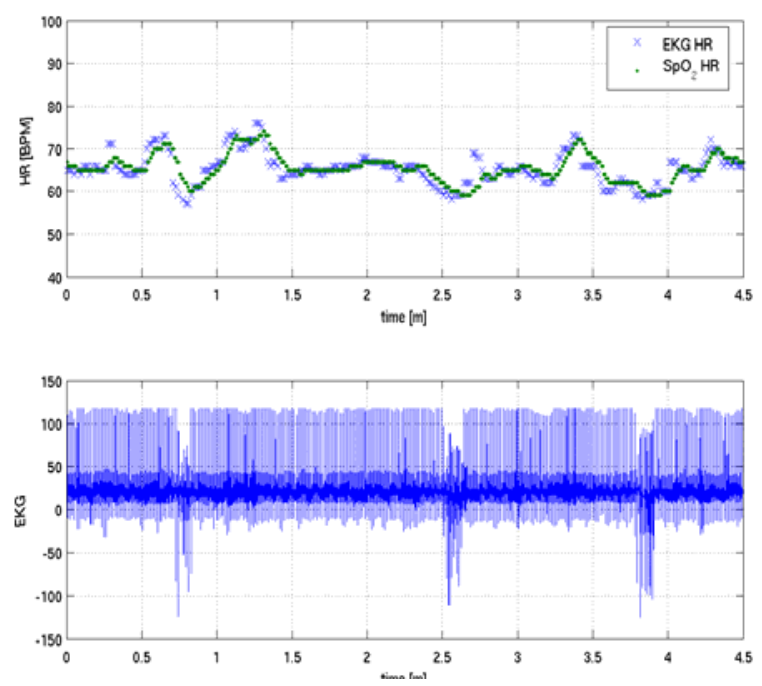

Figure 5: Recorded pacemaker activity when HR dropped under 60 BPM. Top: ECG and $\mathrm{SpO}_{2}$ derived HR. Bottom: ECG tracing

\section{RELATED WORK}

Physiological signal monitoring via portable devices is currently available. There is one commercial system offered by Welch Allyn ${ }^{\circledR}$, the Micropaq ${ }^{\circledR}$ Monitor [29] that monitors patient electrocardiogram (ECG) signals and is used in some hospital wards. Both SMART and two other research systems for vital sign monitoring were developed for disaster environments (WIISARD [2, 16, 17] and AID-N [13, 14, 20]). These two systems were implemented during the same time-frame as the SMART system. There are three systems developed for military applications (Artemis [3], BMIST-J [4] and TACMEDCS [22]), as well as two systems for physiological monitoring developed by researchers: Telcordia ${ }^{\circledR}$ T2 [5] and a system developed at National Taiwan University [18]. Also related to our efforts is ER-One [11], a collection of specifications for disaster response. With the exception of the Welch Allyn ${ }^{\circledR}$ commercial system, evaluation of these systems with significant numbers of real patients has been limited. These systems collect physiological data, may or may not have a location component, and, for the most part do not have a targeted alerting component. The sensors used vary, as does the organization of the software infrastructure. A more detailed comparison of goals and major differences in features of these systems is available in [7]. 


\section{CONCLUSION}

In summary, SMART provides a viable method for monitoring atrisk patients in the waiting areas of an emergency room. We found that having a paramedic on site, while unplanned for initially, was a plus. In addition to getting patient consents, he allowed the SMART system to be studied without burdening the ED staff. While he monitored no more than four patients concurrently, we believe that he could monitor more and, with better false alarm management, the system would scale well. We were also pleasantly surprised that the waist pack was acceptable to patients and that they felt safer with it and would wear it again.

We also used the SMART system in a disaster drill [8]. We set up at BWH and monitored seven healthy individuals who were acting as patients. The SMART system and the SMART Operator freed other hospital staff from having to monitor these patients.

The goals for our future work include

- refining our algorithms to reduce the number of false positives

- $\quad$ redesigning the Patient PDA to increase its battery life

- exploring other sensors, such as blood pressure or hydration

- $\quad$ characterizing the behavior of the system under load

- $\quad$ assessing the wireless networking usage by the system in large areas, such as convention halls used to receive disaster victims

\section{ACKNOWLEDGMENTS}

This work was supported in part by the National Library of Medicine, N01LM33509. Thanks to Esteban Pino of the University of Concepcion in Chile for help in designing and implementing the SMART system We would like to thank the following collaborators for their efforts in earlier phases of this project: Greg Harfst, Robert P. Fischer, Pankaj Sarin, Jennifer Morrissey, Ediza Giraldez, Robert El-Kareh, Hari Balakrishnan, Michel Goraczko and the Cricket team, HP® CRL, Michael Blechner, Craig Schaffert, and Jennifer Carlisle. The indoor location system would not have been deployed without the support from Terry Aasen, the Sonitor ${ }^{\circledR}$ team, and Staal Vinterbo. We also thank Stephen J. Nelson and the Stratus Center at Brigham and Women's Hospital for the opportunity to collect data from their simulated patient, Rosa Figueroa for her comments on 'this paper and for building a data visualization tool and Sheila Marian for proofreading.

\section{REFERENCES}

[1] Analog Devices Low Cost, Low Power Instrumentation Amplifier AD620 datasheet. [accessed 2007 Oct 25]. DOI= http://www.analog.com/UploadedFiles/Data_Sheets/37 793330023930AD620_e.pdf

[2] Arisoylu, M., Mishra, R., Rao, R., Lenert, L.A.. 2005. 802.11 wireless infrastructure to enhance medical response to disasters. In AMIA Annu Symp Proc. (Washington, D.C., USA, October 22-26, 2005). AMIA 2005. American Medical Informatics Association, Bethesda, MD, USA, 1-5.
[3] ARTEMIS home page. Trustees of Dartmouth College; [accessed 2007 Sep 27]. DOI=

http://www.ists.dartmouth.edu/projects/frsensors/artemis

[4] BMIST-J home page. Battlefield Medical Information System Tactical - Joint; [accessed 2007 Sep 27]. DOI= http://www.tatrc.org/website_bmist/index.html

[5] Chen C.M., Agrawal H., Cochinwala M., Rosenbluth D. Stream query processing for healthcare bio-sensor applications. 2004. In Proceedings of the 20th International Conference on Data Engineering (Boston, MA, USA, March 30 - April 2, 2004). ICDE 04. IEEE Computer Society, Washington, D.C., USA, 791-4.

[6] Crossbow ${ }^{\circledR}$ Technologies, Inc. home page. Wireless sensor networks; [accessed 2007 Sep 27]. DOI= http://www.xbow.com

[7] Curtis, D.W., Pino, E.J., Bailey, J.M., Shih, E.I., Waterman, J., Vinterbo, S.A., Stair, T.O., Guttag, J.V., Greenes, R.A., Ohno-Machado, L. 2007. SMART --- an integrated, wireless system for monitoring unattended patients. J Am Med Inform Assoc., Jan.2008.

[8] Daniel M, Drill will be gauge of terror readiness. 2006. The Boston Globe. 2006 Aug 29 [accessed 2007 Sep 27].

Available from: http://www.boston.com/news/local/massach usetts/articles/2006/08/29/drill_will_be_gauge_of_terror_rea diness/

[9] DARPA Internet Program. Transmission Control Protocol. RFC 793, 1981.

[10] Englese, W.A.H. and Zeelenberg, C. 1979. A single scan algorithm for QRS detection and feature extraction. Computers in Cardiology; 6, (1979);37-42

[11] ER One project web page. Washington Hospital Center; [accessed 2007 Sep 27]. Available from: http://www. whcenter.org/body.cfm?id=555603.

[12] Familiar Linux home page. [accessed 2007 Oct 25]. DOI= http://familiar.handhelds.org/

[13] Gao, T., Greenspan, D., Welsh, M., Juang, R., Alm, A. 2005. Vital signs monitoring and patient tracking over a wireless network. In Conf Proc IEEE Eng Med Biol Soc. (Shanghai, China, September, 1-4, 2005 IEEE EMBS 2005. IEEE Computer Society, Washington, D.C., USA, 102-5.

[14] Gao, T., Kim, M.I., White, D.M., Alm, A.M. 2006. Iterative user-centered design of a next generation patient monitoring system for emergency medical response. AMIA Annu Symp Proc. (Washington, D.C., USA, November 11-15, 2006). AMIA 2006. American Medical Informatics Association, Bethesda, MD, USA, 284-8.

[15] IOM. The Future of Emergency Care: Key Findings and Recommendations. Fact Sheet, Institute of Medicine. June 2006; [accessed 2008 Jan 16]. DOI=http://www.iom.edu/Object.File/Master/35/040/Emerg ency\%20Care\%20Findings\%20and\%20Recs.pdf

[16] Killeen, J.P., Chan, T.C., Buono, C., Griswold, W.G., Lenert, L.A. 2006. A wireless first responder handheld device for rapid triage, patient assessment and documentation during mass casualty incidents. AMIA Annu Symp Proc (Washington, D.C., USA, November 11-15, 
2006). AMIA 2006. American Medical Informatics Association, Bethesda, MD, USA, 429-33.

[17] Lenert, L.A., Palmer, D.A., Chan, T.C., Rao, R. 2005. An Intelligent 802.11 Triage Tag for medical response to disasters. In AMIA Annu Symp Proc. (Washington, D.C., USA, Octber 22-26, 2005). AMIA 2005. American Medical Informatics Association, Bethesda, MD, USA, 440-4.

[18] Lin, Y.H., Jan, I.C., Ko, P.C., Chen, Y.Y., Wong, J.M., Jan, G.J. 2004. A wireless PDA-based physiological monitoring system for patient transport, IEEE T Inf Technol B, 8,4 (Dec. 2004 ), 439-47.

[19] McCraig, L.F., Burt, C.W. National hospital ambulatory medical care survey: 2003 emergency department summary. Adv data. 2005 May 26;(358):1. US Dept of HHS. Centers for Disease Control and Prevention; [accessed 2008 Jan 16]. DOI=http://www.cdc.gov/nchs/data/ad/ad358.pdf

[20] Massey, T., Gao, T., Welsh, M., Sharp, J.H., Sarrafzadeh, M. 2006. The design of a decentralized electronic triage system. In AMIA Annu Symp Proc. (Washington, D.C., USA, November 11-15, 2006). AMIA 2006. American Medical Informatics Association, Bethesda, MD, USA, 544-8.

[21] Mills, D.L. Internet time synchronization: the Network Time Protocol. IEEE Trans. Communications COM-39, 10 (October 1991), 1482-1493.

[22] Munsey, C. New tracking system relays casualty data from battlefield. TACMEDCS Navy Times March 2004; c2004 [accessed 2007 Sep 27]. DOI= htt p://www.namrl.navy.mil/NAMRL_NEW_NEWS/TACMED CS\%20Navy\%20Times\%20March\%202004.htm

[23] Nonin ${ }^{\circledR}$ home page. Nonin ${ }^{\circledR}$ Medical, Inc.; c2007 [accessed 2007 Sep 27]. DOI= http://www.nonin.com
[24] Pino, E., Ohno-Machado, L., Wiechmann, E., and Curtis, D. Real-time ECG algorithms for ambulatory patient monitoring. 2005. In AMIA Annu Symp Proc. (Washington, D.C., USA, October 22-26, 2005). AMIA 2005. American Medical Informatics Association, Bethesda, MD, USA, 6048.

[25] Priyantha, N.B., Chakraborty, A., Balakrishnan, H. 2000. The Cricket location-support system. Proceedings of the 6th annual international conference on Mobile computing and networking (MOBICOM), Boston, MA, Aug 2000. p32-43. Cricket home page [accessed 2007 Sep 27] DOI= http://cricket.csail.mit.edu

[26] Sonitor ${ }^{\circledR}$ home page. Sonitor ${ }^{\circledR}$ Technologies Inc. ; c2007 [accessed 2007 Sep 27]. DOI= http://www.sonitor.com/

[27] Tanabe, P., Travers, D., Gilboy, N., Rosenau, A., Sierzega, G., Rupp, V., et al. 2005. Refining Emergency Severity Index triage criteria. Acad Emerg Med. 12, 6 (Jun. 2005), 497-501.

[28] Weaver, A.C. 2006. Secure Sockets Layer. Computer 39, 4 (Apr. 2006), 88-90. DOI= http://dx.doi.org/10.1109/MC.2006.138

[29] Welch Allyn ${ }^{\circledR}$ Micropaq ${ }^{\circledR}$ Monitor Model Micropaq 404 Monitor $\left(\mathrm{ECG} / \mathrm{SpO}_{2}\right)$. Directions for use; [accessed 2007 Sep 27]. DOI= http://www.welchally n.com/documents/Patient\%20Monitoring/Continuous\%20Mo nitoring/Micropaq/usermanual_20070615_402_404_micropa q.pdf

[30] Wuerz, R.C., Milne, L.W., Eitel, D.R., Travers, D., Gilboy, N. 2000. Reliability and validity of a new five-level triage instrument. Acad Emerg Med. 7,3 (Mar. 2000), 236-42. 